\title{
Residues in the $\mathrm{H}^{+}$Translocation Site Define the $\mathrm{p} K_{\mathrm{a}}$ for Sugar Binding to LacY†
}

\author{
Irina Smirnova $\ddagger$, Vladimir Kasho $\ddagger$, Junichi Sugihara ${ }^{\ddagger}$, Jun-Yong Choe ${ }^{\|}$, and $\mathbf{H}$. Ronald \\ Kaback $^{*}, \ddagger, \S, \perp$ \\ ¥Department of Physiology, University of California Los Angeles, Los Angeles, California \\ 90095-7327 \\ §Department of Microbiology, Immunology, and Molecular Genetics, University of California Los \\ Angeles, Los Angeles, California 90095-7327
}

"Department of Biochemistry and Molecular Biology, Rosalind Franklin University of Medicine and Science, The Chicago Medical School, North Chicago, Illinois 60064

${ }^{\perp}$ Molecular Biology Institute, University of California Los Angeles, Los Angeles, California 90095-7327

\section{Abstract}

A remarkably high $\mathrm{p} K_{\mathrm{a}}$ of approximately 10.5 has been determined for sugar-binding affinity to the lactose permease of Escherichia coli (LacY), indicating that, under physiological conditions, substrate binds to fully protonated LacY. We have now systematically tested site-directed replacements for the residues involved in sugar binding, as well as $\mathrm{H}^{+}$translocation and coupling, in order to determine which residues may be responsible for this alkaline $\mathrm{p} K_{\mathrm{a}}$. Mutations in the sugarbinding site (Glu126, Trp151, Glu269) markedly decrease affinity for sugar but do not alter the $\mathrm{p} K_{\mathrm{a}}$ for binding. In contrast, replacements for residues involved in $\mathrm{H}^{+}$translocation (Arg302, Tyr236, His322, Asp240, Glu325, Lys319) exhibit $\mathrm{p} K_{\mathrm{a}}$ values for sugar binding that are either shifted toward neutral $\mathrm{pH}$ or independent of $\mathrm{pH}$. Values for the apparent dissociation constant for sugar binding $\left(K_{\mathrm{d}}^{\mathrm{app}}\right)$ increase greatly for all mutants except neutral replacements for Glu325 or Lys319, which are characterized by remarkably high affinity sugar binding (i.e., low $K_{\mathrm{d}}{ }^{\text {app}}$ ) from $\mathrm{pH} 5.5$ to $\mathrm{pH} 11$. The $\mathrm{pH}$ dependence of the on- and off-rate constants for sugar binding measured directly by stoppedflow fluorometry implicates $k_{\text {off }}$ as a major factor for the affinity change at alkaline $\mathrm{pH}$ and confirms the effects of $\mathrm{pH}$ on $K_{\mathrm{d}}$ app inferred from steady-state fluorometry. These results indicate that the high $\mathrm{p} K_{\mathrm{a}}$ for sugar binding by wild-type LacY cannot be ascribed to any single amino acid residue but appears to reside within a complex of residues involved in $\mathrm{H}^{+}$translocation. There is structural evidence for water bound in this complex, and the water could be the site of protonation responsible for the $\mathrm{pH}$ dependence of sugar binding.

The lactose permease of Escherichia coli $(\mathrm{LacY})^{1}$ is a member of the major facilitator superfamily (MFS) of membrane transport proteins $(1,2)$ that can utilize the free energy of an electrochemical $\mathrm{H}^{+}$gradient $\left(\Delta \tilde{\mu}_{\mathrm{H}^{+}}\right)$to drive uphill accumulation of galactopyranosides (3-9). Alternatively, downhill transport of sugar can drive uphill transport of $\mathrm{H}^{+}$with generation of $\Delta \tilde{\mu}_{\mathrm{H}^{+}}$, the polarity of which depends on the direction of the sugar concentration gradient $(10$,

\footnotetext{
$\dagger$ This work was supported by NIH Grants DK51131, DK069463, GM073210, and GM074929, as well as NSF Grant 0450970 to H.R.K. CXXXX American Chemical Society

*Corresponding author: rkaback@ mednet.ucla.edu; phone, (310) 206-5053; fax, (310) 206-8623.
} 
11). Sugar $/ \mathrm{H}^{+}$symport is tightly coupled with a stoichiometry approximating unity $(4,12,13)$. Cys-scanning and site-directed mutagenesis has shown that a relatively small number of amino acid side chains are irreplaceable with respect to active transport (14). Thus, Glu126 (helix IV), Arg144 (helix V), Glu269 (helix VIII), Arg302 (helix IX), His322, and Glu325 (helix X) have been implicated as key participants in substrate binding and/or $\mathrm{H}^{+}$translocation (7). Trp151 (helix V) is also critically involved in sugar binding, undergoing aromatic stacking with the galactopyranoside ring and also H-bonding with Glu269 $(15,16)$.

Glu126, Arg144, Trp151, and Glu269 form the galactopyranoside-binding/recognition site (17-19), which is located in the middle of the molecule and at the apex of a large hydrophilic cavity open to the cytoplasm (Figure 1A,B, green sticks). $\mathrm{H}^{+}$translocation involves residues primarily in the $\mathrm{C}$-terminal six-helix bundle, which are positioned across the cavity from the sugar-binding site (Figure 1A,B, cyan sticks). Arg302 (helix IX), His322 (helix X), Tyr236 (helix VII), Glu325 (helix X), Asp240 (helix VII), and Lys319 (helix X) form a H-bond/salt bridge network between helices VII, IX, and X (Figure 1C). Arg302, Tyr236, His322, and Asp240 are within $3 \AA$ of each other, and Glu325 and Lys319 flank the network from the cytoplasmic and periplasmic sides, respectively. A charge pair between Asp237 and Lys358 connects helices VII and XI and is important for membrane insertion and stability of LacY but not for sugar/ $\mathrm{H}^{+}$symport (20-22).

LacY is a highly dynamic transport protein in which the sugar and $\mathrm{H}^{+}$binding sites become alternatively accessible to the periplasmic and the cytoplasmic sides of the membrane ( 9 , 23-27). Despite the availability of high-resolution, three-dimensional structures of LacY and a wealth of biochemical data, the mechanism of the coupling of sugar transport to $\mathrm{H}^{+}$ translocation and of $\mathrm{H}^{+}$translocation itself remains unclear.

The finding that LacY affinity for galactopyranosides decreases at the alkaline $\mathrm{pH}(28,29)$ with a $\mathrm{p} K_{\mathrm{a}}$ of about 10.5 (30) and numerous other observations (reviewed in refs 7 and 9) indicate that protonation of LacY is required for sugar binding. Because the $K_{\mathrm{d}}^{\text {app }}$ remains constant

\footnotetext{
${ }^{1}$ Abbreviations:

LacY

lactose $/ \mathrm{H}^{+}$symporter from Escherichia coli

WT

wild type

DDM

dodecyl $\beta$-D-maltopyranoside

TDG

$\beta$-D-galactopyranosyl-1-thio- $\beta$-D-galactopyranoside

NPG

4-nitrophenyl $\alpha$-D-galactopyranoside

MIANS

2-(4'-maleimidylanilino)naphthalene-6-sulfonic acid sodium salt

DACM

$N$-(7-dimethylamino-4-methylcoumarin-3-yl)maleimide

$K_{\mathbf{d}}$ app

apparent dissociation constant

TRP $\rightarrow$ NPG FRET

Förster resonance energy transfer from Trp to NPG

$\Delta \tilde{\mu}_{\mathrm{H}^{+}}$

electrochemical $\mathrm{H}^{+}$gradient
} 
from $\mathrm{pH} 5.5$ to $\mathrm{pH} 9.0$, it follows that under physiological conditions LacY is fully protonated with respect to sugar binding. Although amino acid side chains with alkaline $\mathrm{p} K_{\mathrm{a}} \mathrm{s}$ such as those of Arg, Lys, or Tyr could be responsible for the high $\mathrm{p} K_{\mathrm{a}}$ of binding, a hydrophobic environment, as well as clustering of amino acyl side chains, can markedly alter the $\mathrm{p} K_{\mathrm{a}} \mathrm{s}$ of ionizable groups in proteins $(31,32)$.

Here we describe the effects of mutations in residues involved in sugar binding and/or $\mathrm{H}^{+}$ translocation on the $\mathrm{p} K_{\mathrm{a}}$ for sugar binding. Since replacement of essential side chains can dramatically decrease sugar affinity $(29,33)$, a highly sensitive fluorometric assay based on galactopyranoside-specific conformational change(s) was used to measure $K_{\mathrm{d}}$ app for galactosides (30). Kinetic parameters of sugar binding were also determined directly by Trp to $p$-nitrophenyl $\alpha$-D-galactopyranoside Förster resonance energy transfer (Trp $\rightarrow$ NPG FRET) combined with stopped flow (34). The $\mathrm{pH}$ dependence of the forward and reverse rate constants indicates that the reverse rate constant $\left(k_{\text {off }}\right)$ is a major determinant of the affinity change at alkaline $\mathrm{pH}$. The findings demonstrate that the high $\mathrm{p} K_{\mathrm{a}}$ observed for sugar binding is not related to the $\mathrm{p} K_{\mathrm{a}}$ of a single amino acid side chain. We suggest that structural water coordinated within the $\mathrm{H}$-bond/salt bridge network in the $\mathrm{C}$-terminal six-helix bundle of LacY may participate in $\mathrm{H}^{+}$translocation as hydronium ion intermediate(s).

\section{MATERIALS AND METHODS}

\section{Materials}

Oligonucleotides were synthesized by Integrated DNA Technologies, Inc. (Coralville, IA). Restriction enzymes were purchased from New England Biolabs (Beverly, MA). The QuickChange II kit was from Stratagene (La Jolla, CA), and $\beta$-D-galactopyranosyl-1-thio- $\beta$-Dgalactopyranoside (TDG) and 4-nitrophenyl $\alpha$-D-galactopyranoside (NPG) were purchased from Sigma (St. Louis, MO). Fluorophores [2-(4'-maleimidylanilino)-naphthalene-6-sulfonic acid (MIANS) and $N$-(7-dimethylamino-4-methylcoumarin-3-yl)maleimide (DACM)] were obtained from Molecular Probes/Invitrogen (Eugene, OR) and from Anaspec (San Jose, CA). Dodecyl $\beta$-D-maltopyranoside (DDM) was obtained from Anatrace (Maumee, $\mathrm{OH}$ ). Talon superflow resin was purchased from BD Clontech (Palo Alto, CA). All other materials were of reagent grade obtained from commercial sources.

\section{Construction of Mutants and Purification of LacY}

Construction of mutants, expression in E. coli, and purification of LacY were performed as described (26). All mutants contained an additional Cys residue (V331C in helix X) for labeling with maleimide-based fluorophores (MIANS or DACM) and a C-terminal 6-His tag that was used for affinity purification with a Talon resin. Purified proteins $(10-15 \mathrm{mg} / \mathrm{mL})$ in $50 \mathrm{mM}$ sodium phosphate $\left(\mathrm{NaP}_{\mathrm{i}} ; \mathrm{pH} 7.5\right) / 0.02 \% \mathrm{DDM}$ were frozen in liquid nitrogen and stored at -80 ${ }^{\circ} \mathrm{C}$ until use.

\section{Labeling with Fluorophores}

Purified LacY mutants (40-50 $\mu \mathrm{M}$ ) were labeled at Cys331 with an equimolar concen-tration of fluorophore in $50 \mathrm{mM} \mathrm{NaP}_{\mathrm{i}}(\mathrm{pH} 7.0) / 0.02 \% \mathrm{DDM}$ in the presence of $15 \mathrm{mM}$ TDG in order to protect Cys148 against alkylation as described (30). Control experiments with wild-type LacY exhibited essentially no labeling by MIANS under the same conditions.

\section{Fluorescence Measurements}

Steady-state fluorescence was monitored at room temperature using an SLM-Aminco 8100 spectrofluorometer (Urbana, IL) modified by OLIS, Inc. (Bogart, GA), and on a SPEX Fluorolog 3 spectrofluorometer (Edison, NY) as described (30) with excitation and emission 
wavelengths, respectively, of 330 and $415 \mathrm{~nm}$ for MIANS or 397 and $440 \mathrm{~nm}$ for DACM. Titrations were recorded after sequential addition of 5-10 $\mu \mathrm{L}$ of concentrated TDG to $2 \mathrm{~mL}$ of protein solution $(0.4 \mu \mathrm{M})$ in $0.02 \% \mathrm{DDM} / 50 \mathrm{mM}$ buffers with over-lapping $\mathrm{pH}$ ranges. The buffers used were citrate- $\mathrm{P}_{\mathrm{i}}\left(\mathrm{pH}\right.$ 5.5-6.5), $\mathrm{NaP}_{\mathrm{i}}$ (pH 6.5-8.0), $N$-(1,1-dimethyl-2-

hydroxyethyl)-3-amino-2-hydroxypropanesulfonic acid (AMPSO) (pH 8.0-9.5), and 3(cyclohexylamino)-1-propanesulfonic acid (CAPS) ( $\mathrm{pH}$ 9.5-11.0). Titration data were corrected for dilution and fluorescence drift at high $\mathrm{pH}$. Data fitting was carried out by using SigmaPlot 10 (Systat Software Inc., Richmond, CA).

Stopped-flow measurements of Trp $\rightarrow$ NPG FRET were performed at $25^{\circ} \mathrm{C}$ using an SLMAminco 8100 spectrofluorometer (Urbana, IL) modified with a USA stopped-flow unit (OLIS, Inc., Bogart, GA) as described (34). Protein concentrations were 0.5-2 $\mu \mathrm{M}$. The same buffers were used as described for steadystate measurements. Typically, protein preincubated at an indicated NPG concentration was rapidly mixed with saturating concentrations of TDG (10-20 $\mathrm{mM}$ after mixing). Six to twelve stopped-flow traces were recorded for each data point, averaged, and fitted with a single exponential equation with the built-in Olis Globalworks software package or with SigmaPlot 10 (Systat Software Inc., Richmond, CA).

\section{Transport Assays}

Lactose accumulation by E. coli T184 expressing wild-type LacY or given mutants was performed as described (35).

\section{Refinement of LacY Structure (PDB ID 2cfq)}

The best available structure of $\mathrm{C} 154 \mathrm{G} \mathrm{LacY}$ was used in a search for the presence of structural water molecules (see Supporting Information Refinement of LacY Structure for details). The refinement included all data in the resolution range from 2.81 to $9.99 \AA$ without $\sigma$ cutoff ( 28407 reflections) available from the deposited structure factor file (2cfq-sf.cif).

\section{RESULTS}

\section{The $\mathrm{pK}_{\mathrm{a}}$ for TDG Binding Does Not Change with Mutations in Residues Directly Involved in Sugar Binding}

As shown previously (30), MIANS-labeled wild-type LacY binds TDG with a $K_{\mathrm{d}}$ app near 1 $\mu \mathrm{M}$ in the $\mathrm{pH}$ range 5.5-8.0; the $K_{\mathrm{d}}$ app is about 5-fold greater at $\mathrm{pH} 9.5$ and 30-fold greater at pH 11.0 (Figure 2; Table 1). Although DACM-labeled LacY exhibits lower affinity (i.e., higher $K_{\mathrm{d}}{ }^{\text {app }}$ ), a similar dependence on $\mathrm{pH}$ is observed (Table 1).

Residues Glu126, Arg144, Trp151, and Glu269 participate directly in sugar binding (Figure 1B, green sticks), and mutation of each drastically decreases TDG-binding affinity (Figure 2, $y$ axes; Table 1; see also Supporting Information Figure 11). Mutations E126A or E126Q completely abolish sugar binding and transport $(36,37)$, thereby precluding studies on the effect of $\mathrm{pH}$. The conservative mutant E126D exhibits a $K_{\mathrm{d}}$ app increased more than 500-fold (Table 1); nevertheless, the $\mathrm{pH}$ dependence of sugar binding remains unchanged (Figure 2A; Table 1). Only the conservative replacement of Glu269 with Asp maintains activity; the mutants E269A, Q, N, H, K, G, and Y exhibit no sugar binding (data not shown). Although the mutant E269D exhibits a $\mathrm{p} K_{\mathrm{a}}$ similar to that of wild type, affinity for TDG decreases about 70 times relative to wild type (Figure 2B; Table 1). The observation is consistent with other evidence $(38,39)$ indicating that Glu269 may directly interact with the galactopyranosyl ring.

Trp151 is important for correctly orientating bound galactopyranosides, and even relatively conservative replacements with Tyr or Phe decrease sugar affinity about 20 or 50 times, respectively (15). Sugar binding by MIANS-labeled mutant W151Y exhibits a pH dependence 
profile similar to wild-type LacY with a $K_{\mathrm{d}}$ app that is about 30 times higher (Figure 2C;Table 1). Cys 154 is located one turn of helix V from Trp151 toward the periplasmic side, and mutant C154G binds sugar but does almost negligible transport because it is paralyzed on the periplasmic side $(25,26,40-42)$. The $\mathrm{pH}$ dependence of sugar binding for the $\mathrm{C} 154 \mathrm{G}$ mutant is also similar to WT LacY, with an increase in $K_{\mathrm{d}}$ app of about 20-fold (Figure 2D).

Arg 144, which likely forms a bidentate H-bond with the 3- and 4-OH groups in the galactopyranoside ring (17), is strictly conserved in related symporters (43). Even replacement with Lys leads to complete loss of sugar binding (36,37). Therefore, replacements for Arg 144 were precluded from this study.

\section{Mutations That Decrease TDG Affinity and Change the $\mathrm{pK}_{\mathrm{a}}$ for Binding}

Arg302, Tyr236, His322, and Asp240 form an H-bond/salt bridge cluster in the middle of the C-terminal six-helix bundle (Figure 1C, cyan sticks), and any single replacement results in a marked decrease in the affinity for sugar and also a concomitant change in the $\mathrm{pH}$ dependence of $K_{\mathrm{d}}$ app (Figure 3; Table 1; see also Supporting Information Figures 12-14). Two distinct effects on the $\mathrm{pH}$ profiles are observed: (i) a significant shift of $\mathrm{pH}$ dependence toward lower $\mathrm{p} K_{\mathrm{a}}$ values, or (ii) suppression of the effect of alkaline $\mathrm{pH}$ on sugar affinity. An acid shift of $1.5-2.5 \mathrm{pH}$ units is observed for mutant R302K (Figure 3A; Table 1) and for all Tyr236 mutants, except Y236F and Y236K (Figure 3C,D; Table 1). $K_{\mathrm{d}}$ app values increase sharply between $\mathrm{pH}$ 7.5 and $\mathrm{pH} 9.5$ and approach a plateau with at least a 10-fold decrease in TDG affinity in each mutant. The other effect, suppression of the increase in $K_{\mathrm{d}}$ app at alkaline $\mathrm{pH}$, is observed with mutant R302A (Figure 3B; Table 1) and for mutants D240N or D240A (Figure 3H; Table 1), as well as for all the His322 replacements (H322K, Y, F, A, N, Q, R; Figure 3E,F; Table 1) and mutants Y236F or Y236K (Figure 3C; Table 1). The only conservative replacement in this group, mutant D240E, does not exhibit a change in $\mathrm{p} K_{\mathrm{a}}$ relative to wild-type LacY (Figure 3G; Table 1). However, sugar affinity in all of these mutants, particularly the replacements for His322, is drastically decreased (Table 1; Figure 3, $y$ axes).

\section{High-Affinity Sugar Binding Independent of pH Is Observed with Neutral Replacements for Lys319 or Glu325}

The most striking effect of mutations is found when Lys 319 or Glu325 is replaced with neutral residues in the mutants K319L, K319Q, E325A, and E325Q (Figure 4; Table 1; see also Supporting Information Figure 15). The affinities are similar to those observed for wild-type $\mathrm{LacY}$ at pH 6-8 and remain high (i.e., low $K_{\mathrm{d}}{ }^{\text {app}}$ ) over the entire $\mathrm{pH}$ range from 5.5 to 11. Mutant E325Q was also tested with DACM-labeled V331C LacY (Figure 4C) with the same result: the high-affinity TDG binding is independent of $\mathrm{pH}$. It is remarkable that elimination of an ionizable side chain at position 319 or 325 results in high-affinity TDG binding even at extremely low $\mathrm{H}^{+}$concentrations.

The affinity for TDG does not change significantly with the mutant K319R (Figure 4A; Table 1) but decreases markedly with the mutant E325D (Figure 4B; Table 1), and both mutants exhibit essentially the same $\mathrm{pH}$ dependence as wild-type LacY. These observations are consistent with the notion that neutral replacements of Glu325 and Lys319 completely block transport with little effect on sugar binding, but the protein with conservative replacements at these positions retains at least partial transport activity $(29,35,44-49)$ (see also Supporting Information Figure 17).

\section{Effect of pH on Pre-Steady-State Kinetics of Direct Sugar Binding}

Rates $\left(k_{\text {obs }}\right)$ of TDG induced conformational change with MIANS-labeled LacY have been shown to increase at alkaline $\mathrm{pH}$. The forward rate $\left(k_{\mathrm{on}}{ }^{\mathrm{app}}\right)$ does not depend on $\mathrm{pH}$, while the reverse rate $\left(k_{\mathrm{off}}^{\mathrm{app}}\right)$ is clearly $\mathrm{pH}$ dependent, resulting in an increase of $K_{\mathrm{d}}^{\mathrm{app}}\left(K_{\mathrm{d}}=k_{\mathrm{off}} / k_{\mathrm{on}}\right)$ 
at alkaline $\mathrm{pH}$ with $\mathrm{p} K_{\mathrm{a}}$ of about 10.5 (30). Consistently, a similar effect of $\mathrm{pH}$ on the kinetic parameters is observed when sugar binding is measured directly by Trp $\rightarrow$ NPG FRET. Protein samples equilibrated with NPG were mixed rapidly with TDG at saturating concentrations, and reverse rate constants $\left(k_{\text {off }}\right)$ were measured directly by recovery of Trp fluorescence after displacement of bound NPG with excess TDG $(30,34)$. Measurement of the reverse rates is convenient for testing the effect of $\mathrm{pH}$ since $k_{\mathrm{off}}$ is concentration independent and slower than $k_{\text {obs }}\left(k_{\mathrm{obs}}=k_{\text {off }}+k_{\mathrm{on}}[\mathrm{NPG}]\right)$. Stopped-flow traces recorded at given $\mathrm{pH}$ values and NPG concentrations for wild-type LacY and mutant K319L are shown in Figure 5. All traces are fitted with a single-exponential equation, which allows estimation of rates and amplitudes of the fluorescence change. The results demonstrate that (i) the rate of NPG displacement $\left(k_{\text {off }}\right)$ is independent of NPG concentration with either wild-type LacY (Figure 5A; $k_{\text {off }}=80 \pm 2$ $\mathrm{s}^{-1}$ for traces 1-4) or the K319L mutant (Figure 5B; $k_{\text {off }}=70 \pm 5 \mathrm{~s}^{-1}$ for traces 1-3), (ii) the amplitudes increase with NPG concentration for both the wild-type LacY (Figure 5A; amplitudes are 9\%, 16\%, 22\%, 25\% for 12, 50, 100, $300 \mu \mathrm{M} \mathrm{NPG}$, respectively) and mutant K319L (Figure 5B; amplitudes are 9\%, 26\%, 33\% for 5, 20, $100 \mu \mathrm{M}$ NPG, respectively), and (iii) the displacement rate $\left(k_{\text {off }}\right)$ increases at alkaline $\mathrm{pH}$ for wild-type LacY (Figure 5C; $k_{\text {off }}$ values are $69 \pm 2 \mathrm{~s}^{-1}, 79 \pm 2 \mathrm{~s}^{-1}, 160 \pm 7 \mathrm{~s}^{-1}, 224 \pm 10 \mathrm{~s}^{-1}$ at $\mathrm{pH} 6.0,9.0,10.25,10.5$, respectively), while $k_{\text {off }}$ hardly changes with mutant K319L (Figure 5D; $k_{\text {off }}$ values are $54 \pm 2 \mathrm{~s}^{-1}, 44 \pm 4$ $\mathrm{s}^{-1}, 69 \pm 10 \mathrm{~s}^{-1}$ at pH 6.0, 9.0, 10.5, respectively).

The concentration dependence of the change in amplitudes with wild-type LacY shows that affinity for NPG decreases at alkaline $\mathrm{pH}$. Thus, $K_{\mathrm{d}}$ values calculated from hyperbolic fits are $43 \pm 5 \mu \mathrm{M}, 30 \pm 2 \mu \mathrm{M}$, and $320 \pm 60 \mu \mathrm{M}$ at pH 7.0, 9.0, and 10.25, respectively (Figure 6A). The $\mathrm{pH}$ dependencies of $k_{\text {off }}$ as measured by stopped flow and $k_{\text {on }}$ calculated from the $K_{\mathrm{d}}$ are presented in Figure 6D. Clearly, $k_{\text {on }}$ is $\mathrm{pH}$ independent $\left(1.5 \pm 0.9 \times 10^{6} \mathrm{M}^{-1} \mathrm{~s}^{-1}\right)$, while $k_{\text {off }}$ increases dramatically at alkaline $\mathrm{pH}$ with $\mathrm{p} K_{\mathrm{a}}$ at about 10.5 . The $\mathrm{pH}$ dependencies of the kinetic constants measured directly here for binding of NPG to unlabeled protein and reported earlier for TDG binding to MIANS-labeled LacY (30) are practically identical: the on-rate is $\mathrm{pH}$ independent, while the off-rate increases at alkaline $\mathrm{pH}$ with $\mathrm{p} K_{\mathrm{a}}$ around 10.5. It follows that the $\mathrm{p} K_{\mathrm{a}}$ of $\sim 10.5$ observed with wild-type LacY is an intrinsic property of the protein that reflects binding specifically and is not due to a conformational change or to labeling with fluorophores.

Neutral replacements for Lys319 or Glu325 practically abolish the effect of $\mathrm{pH}$ on the kinetic parameters for NPG binding. $K_{\mathrm{d}}$ values estimated from the effect of NPG concentration on fluorescence amplitude are similar to the $K_{\mathrm{d}}$ for wild-type $\mathrm{LacY}$ at neutral $\mathrm{pH}$ but do not change significantly at alkaline $\mathrm{pH}$ (Figure 6B,C; Figure 7A-C). Unlike with wild-type LacY, $k_{\text {off }}$ is essentially unchanged in the $\mathrm{pH}$ range from 6 to 10.8 (compare Figure 6D with Figure 6E,F and Figure 7D-F). The displacement rate measured in each experiment represents a true value of $k_{\text {off }}$ since it is not different from the $k_{\text {off }}$ value obtained from the dependence of $k_{\text {obs }}$ on NPG concentration (see Figure 8 for example). Calculated $k_{\text {on }}$ values for all these mutants are also unaffected by $\mathrm{pH}$. These data provide strong support for the remarkable conclusion that neutral replacements for Lys319 or Glu325 in LacY result in high-affinity sugar binding even at $\mathrm{pH}$ 11.

All replacements for amino acid side chains involved in the H-bond/salt bridge cluster ( $\operatorname{Arg} 302$, Tyr236, His322, or Asp240) decrease sugar affinity (Table 1), thereby complicating presteady-state measurements. Nevertheless, the $\mathrm{pH}$ dependence of kinetic parameters for NPG binding was measured directly for R302A, D240E, and D240A mutants (Figure 9). The pH dependence of $k_{\text {off }}$ for each mutant is very similar to the $\mathrm{pH}$ dependence of the $K_{\mathrm{d}}$ app obtained with the corresponding MIANS-labeled protein. R302A and D240A demonstrate little change of $k_{\text {off }}$ with $\mathrm{pH}$, while E240E exhibits a sharp increase of the displacement rate in alkaline $\mathrm{pH}$ (compare Figure 9D-F, respectively, with Figure 3B, G,H). Clearly, the rate of sugar release 
$\left(k_{\text {off }}\right)$ is a key parameter, which is primarily affected by the protonation state of the H-bond/ salt bridge cluster that defines the $\mathrm{pH}$ dependence of the $K_{\mathrm{d}}$ app

\section{DISCUSSION}

LacY binds galactopyranosides specifically in a manner that is $\mathrm{pH}$ dependent $(28,29)$, and protonation is required for high-affinity binding (reviewed in refs 7 and 9). In addition, it has been shown recently (30) that various galactopyranosides bind to wild-type LacY with $\mathrm{p} K_{\mathrm{a}}$ of about 10.5, indicating that at physiological $\mathrm{pH} \mathrm{LacY}$ is protonated. There are several irreplaceable amino acid side chains involved in sugar binding and/or $\mathrm{H}^{+}$translocation that may be responsible for the alkaline $\mathrm{p} K_{\mathrm{a}}$. However, as revealed by the studies presented here, the $\mathrm{p} K_{\mathrm{a}}$ cannot be assigned to a single amino acid side chain in this group. Although conservative replacement of the side chains directly involved in sugar binding greatly decreases affinity, each replacement exhibits the same $\mathrm{pH}$ dependence for TDG affinity as wildtype LacY (Figure 2). Furthermore, Arg302, Tyr236, His322, and Asp240, which do not make direct contact with the galactopyranosyl ring (17), are important for affinity nonetheless, because all replacements markedly increase $K_{\mathrm{d}}$ (Figure 3;Table 1 ). The conservative mutations R302K or Y236W cause acidic shifts in $\mathrm{p} K_{\mathrm{a}}$ by ca. $2 \mathrm{pH}$ units (Figure 3A,C). Replacements of Tyr236 with nonaromatic amino acids also cause an acid shift in $\mathrm{p} K_{\mathrm{a}}$ (Figure 3D). However, Y236F or Y236K, as well as uncharged replacements for Arg302 or Asp240 and all replacements for His322, exhibit low-affinity TDG binding that is largely independent of $\mathrm{pH}$ (Figure 3;Table 1). These results indicate that protonation of individual amino acid residues does not determine $\mathrm{p} K_{\mathrm{a}}$ for sugar-binding affinity in LacY, unlike in the case of KcsA channel where a clear effect of selected mutations in the $\mathrm{H}^{+}$binding cluster on $\mathrm{pH}$ sensitivity is observed (50).

Remarkably, neutral replacements for either Glu325 or Lys319 result in high-affinity galactoside binding over the entire $\mathrm{pH}$ range tested (Table 1; Figure 4; Figure 6B,C; Figure 7A-C; Figure 8). In contrast, conservative replacements at these positions exhibit decreased affinity, but $\mathrm{pH}$ dependencies are similar to wild-type LacY. Uncharged side chain replacements at positions $325(29,44,45,48,49)$ or $319(46)$ block all reactions that require net $\mathrm{H}^{+}$translocation with little or no effect on equilibrium exchange or counterflow. Pre-steadystate kinetic analysis indicates that the rate of sugar release rises sharply at alkaline $\mathrm{pH}$ with wild-type LacY, while it remains practically constant in the $\mathrm{pH}$ range 6-11 with uncharged mutants of Glu325 or Lys319. Therefore, the $\mathrm{pH}$ dependence of sugar affinity is determined by the $k_{\text {off }}$ value, since $k_{\text {on }}$ remains constant for wild-type LacY and the mutants studied. Notably, similar studies on the $\mathrm{H}^{+}$-coupled multidrug antiporter EmrE indicate that the $k_{\text {off }}$ for tetraphenylphosphonium does not depend on $\mathrm{pH}$, while $k_{\mathrm{on}}$ increases markedly at alkaline $\mathrm{pH}$ so that affinity increases dramatically ( $K_{\mathrm{d}}$ decreases) (51). In other words, the effects of $\mathrm{pH}$ on substrate binding kinetic parameters of EmrE are exactly opposite from those observed with LacY.

The residues involved in $\mathrm{H}^{+}$translocation in LacY do not form a pathway through the membrane (Figure 1) (9). Rather Arg302, His322, Tyr236, and Asp240 form a tightly interconnected H-bond/salt bridge cluster in the middle of the molecule with Glu325 and Lys 319 within $5 \AA$ A on opposite sides (Figure 1C). Any disturbance in the central core of the $\mathrm{H}^{+}$translocation site decreases sugar affinity by affecting $\mathrm{H}^{+}$binding, while uncharged side chains at positions 325 or 319 prevent $\mathrm{H}^{+}$escape from the cluster and maintain coupling with the sugar-binding site that retains high affinity even at very alkaline $\mathrm{pH}$. Since no single amino acid residue in the central cluster of Arg302, His322, Tyr236, and Asp240 can be identified as an individual $\mathrm{H}^{+}$acceptor, perhaps coordinated water molecules within the $\mathrm{H}^{+}$binding site form a hydronium ion intermediate that cannot be deprotonated with neutral replacements for Lys 319 or Glu325. By this means, water may behave like a cofactor in $\mathrm{H}^{+}$translocation. 
Such a notion may also explain the phenotypes of the mutants in the $\mathrm{H}^{+}$translocation site. Mutants with neutral replacements for Glu325 or Lys319 catalyze equilibrium exchange and counterflow because LacY remains protonated, while replacement of the other side chains in the H-bond/salt bridge cluster results in loss of coordinated water molecule(s) so that LacY protonation and coupled sugar binding are impaired. Involvement of hydronium ions in $\mathrm{H}^{+}$ binding and translocation was proposed originally by Boyer for $F_{1} / F_{0}-$ ATPase (52) and used recently by von Ballmoos and Dimroth (53) to explain the unexpectedly high $\mathrm{p} K_{\mathrm{a}}$ for the conserved carboxylic acid in the $\mathrm{C}$ subunit of the enzyme. Structural water molecules coordinating $\mathrm{H}^{+}$within the hydrophobic core of bacteriorhodopsin have also been identified $(54,55)$.

The electron density map of the amino acid residues involved in $\mathrm{H}^{+}$translocation is welldefined in all X-ray structures of LacY (17-19). Therefore, the structure of C154G LacY with the best overall resolution $2.95 \AA$ (PDB ID 2cfq) (18) is reanalyzed here, and the refinements included additional reflections to $2.81 \AA$ that were omitted originally (see Supporting Information Refinement of LacY Structure for details). There are two strong globular densities within the $\mathrm{H}^{+}$binding site in the composite omit map (over $5 \sigma$ contour level) consistent with single water molecules (Figure 10). One water molecule forms an H-bond with Asp240 and another with Lys319 and Thr265 (Figure 10, broken lines). These structural water molecules liganded by residues in the $\mathrm{H}^{+}$binding site may be important as hydronium ion intermediates during sugar $/ \mathrm{H}^{+}$symport. Moreover, Thr 265 is located in helix VIII one turn from irreplaceable Glu269, so that the water molecule connecting Lys319 and Thr265 may participate in the coupling between protonation and sugar binding.

\section{Supplementary Material}

Refer to Web version on PubMed Central for supplementary material.

\section{Acknowledgments}

We are indebted to Dr. Douglas Rees (California Institute of Technology) for helpful discussions regarding the refined crystal structure of LacY.

\section{REFERENCES}

1. Saier MH Jr. Beatty JT, Goffeau A, Harley KT, Heijne WH, Huang SC, Jack DL, Jahn PS, Lew K, Liu J, Pao SS, Paulsen IT, Tseng TT, Virk PS. The major facilitator superfamily. J. Mol. Microbiol. Biotechnol 1999;1:257-279. [PubMed: 10943556]

2. Saier MH Jr. Families of transmembrane sugar transport proteins. Mol. Microbiol 2000;35:699-710. [PubMed: 10692148]

3. West IC. Lactose transport coupled to proton movements in Escherichia coli. Biochem. Biophys. Res. Commun 1970;41:655-661. [PubMed: 4920870]

4. West IC, Mitchell P. Stoichiometry of lactose- $\mathrm{H}^{+}$symport across the plasma membrane of Escherichia coli. Biochem. J 1973:132.

5. Foster DL, Garcia ML, Newman MJ, Patel L, Kaback HR. Lactose-proton symport by purified lac carrier protein. Biochemistry 1982;21:5634-5638. [PubMed: 6293552]

6. Kaback HR. The lac carrier protein in Escherichia coli: From membrane to molecule. J. Membr. Biol 1983;76:95-112. [PubMed: 6358502]

7. Kaback HR, Sahin-Toth M, Weinglass AB. The kamikaze approach to membrane transport. Nat. Rev. Mol. Cell. Biol 2001;2:610-620. [PubMed: 11483994]

8. Kaback HR. Structure and mechanism of the lactose permease. C. R. Biol 2005;328:557-567. [PubMed: 15950162]

9. Guan L, Kaback HR. Lessons from lactose permease. Annu. Rev. Biophys. Biomol. Struct 2006;35:6791. [PubMed: 16689628] 
10. Garcia ML, Viitanen P, Foster DL, Kaback HR. Mechanism of lactose translocation in proteoliposomes reconstituted with lac carrier protein purified from Escherichia coli. 1. Effect of $\mathrm{pH}$ and imposed membrane potential on efflux, exchange, and counterflow. Biochemistry 1983;22:2524-2531. [PubMed: 6344920]

11. Kaczorowski GJ, Robertson DE, Kaback HR. Mechanism of lactose translocation in membrane vesicles from Escherichia coli. 2. Effect of imposed delta psi, delta $\mathrm{pH}$, and delta $\mathrm{mu} \mathrm{H}^{+}$Biochemistry 1979;18:3697-3704. [PubMed: 38837]

12. Zilberstein D, Schuldiner S, Padan E. Proton electrochemical gradient in Escherichia coli cells and its relation to active transport of lactose. Biochemistry 1979;18:669-673. [PubMed: 33700]

13. Patel L, Garcia ML, Kaback HR. Direct measurement of lactose/proton symport in Escherichia coli membrane vesicles: Further evidence for the involvement of histidine residue(s). Biochemistry 1982;21:5805-5810. [PubMed: 6295442]

14. Frillingos S, Sahin-Toth M, Wu J, Kaback HR. Cys-scanning mutagenesis: A novel approach to structure function relationships in polytopic membrane proteins. FASEB J 1998;12:1281-1299. [PubMed: 9761772]

15. Guan L, Hu Y, Kaback HR. Aromatic stacking in the sugar binding site of the lactose permease. Biochemistry 2003;42:1377-1382. [PubMed: 12578349]

16. Vazquez-Ibar JL, Guan L, Weinglass AB, Verner G, Gordillo R, Kaback HR. Sugar recognition by the lactose permease of Escherichia coli. J. Biol. Chem 2004;279:49214-49221. [PubMed: 15364943]

17. Abramson J, Smirnova I, Kasho V, Verner G, Kaback HR, Iwata S. Structure and mechanism of the lactose permease of Escherichia coli. Science 2003;301:610-615. [PubMed: 12893935]

18. Mirza O, Guan L, Verner G, Iwata S, Kaback HR. Structural evidence for induced fit and a mechanism for sugar/H(+) symport in LacY. EMBO J 2006;25:1177-1183. [PubMed: 16525509]

19. Guan L, Mirza O, Verner G, Iwata S, Kaback HR. Structural determination of wild-type lactose permease. Proc. Natl. Acad. Sci. U.S.A 2007;104:15294-15298. [PubMed: 17881559]

20. Dunten RL, Sahin-Tóth M, Kaback HR. Role of the charge pair formed by aspartic acid 237 and lysine 358 in the lactose permease of Escherichia coli. Biochemistry 1993;32:3139-3145. [PubMed: 8457574]

21. Frillingos S, Sahin-Tóth M, Lengeler JW, Kaback HR. Helix packing in the sucrose permease of Escherichia coli: Properties of engineered charge pairs between helices VII and XI. Biochemistry 1995;34:9368-9373. [PubMed: 7626606]

22. He MM, Voss J, Hubbell WL, Kaback HR. Use of designed metal-binding sites to study helix proximity in the lactose permease of Escherichia coli. 1. Proximity of helix VII (Asp237 and Asp240) with helices X (Lys319) and XI (Lys358). Biochemistry 1995;34:15661-15666. [PubMed: 7495795]

23. Abramson J, Smirnova I, Kasho V, Verner G, Iwata S, Kaback HR. The lactose permease of Escherichia coli: Overall structure, the sugar-binding site and the alternating access model for transport. FEBS Lett 2003;555:96-101. [PubMed: 14630326]

24. Kaback HR, Dunten R, Frillingos S, Venkatesan P, Kwaw I, Zhang W, Ermolova N. Site-directed alkylation and the alternating access model for LacY. Proc. Natl. Acad. Sci. U.S.A 2007;104:1650416509. [PubMed: 17925435]

25. Majumdar DS, Smirnova I, Kasho V, Nir E, Kong X, Weiss S, Kaback HR. Single-molecule FRET reveals sugar-induced conformational dynamics in LacY. Proc. Natl. Acad. Sci. U.S.A 2007;104:12640-12645. [PubMed: 17502603]

26. Smirnova I, Kasho V, Choe JY, Altenbach C, Hubbell WL, Kaback HR. Sugar binding induces an outward facing conformation of LacY. Proc. Natl. Acad. Sci. U.S.A 2007;104:16504-16509. [PubMed: 17925435]

27. Zhou Y, Guan L, Freites JA, Kaback HR. Opening and closing of the periplasmic gate in lactose permease. Proc. Natl. Acad. Sci. U.S.A 2008;105:3774-3778. [PubMed: 18319336]

28. Yamato I, Rosenbusch JP. Dependence on $\mathrm{pH}$ of substrate binding to lactose carrier in Escherichia coli cytoplasmic membranes. FEBS Lett 1983;151:102-104. [PubMed: 6297984]

29. Sahin-Tóth M, Karlin A, Kaback HR. Unraveling the mechanism of lactose permease of Escherichia coli. Proc. Natl. Acad. Sci. U.S.A 2000;97:10729-10732. [PubMed: 10984523] 
30. Smirnova IN, Kasho V, Kaback HR. Protonation and sugar binding to LacY. Proc. Natl. Acad. Sci. U.S.A 2008;105:8896-8901. [PubMed: 18567672]

31. Fitch CA, Karp DA, Lee KK, Stites WE, Lattman EE, Garcia-Moreno EB. Experimental pK(a) values of buried residues: Analysis with continuum methods and role of water penetration. Biophys. J 2002;82:3289-3304. [PubMed: 12023252]

32. Baran KL, Chimenti MS, Schlessman JL, Fitch CA, Herbst KJ, Garcia-Moreno BE. Electrostatic effects in a network of polar and ionizable groups in staphylococcal nuclease. J. Mol. Biol 2008;379:1045-1062. [PubMed: 18499123]

33. He M, Kaback HR. Interaction between residues Glu269 (helix VIII) and His322 (helix X) of the lactose permease of Escherichia coli is essential for substrate binding. Biochemistry 1997;36:1368813692. [PubMed: 9354639]

34. Smirnova IN, Kasho VN, Kaback HR. Direct sugar binding to LacY measured by resonance energy transfer. Biochemistry 2006;45:15279-15287. [PubMed: 17176050]

35. Weinglass AB, Smirnova IN, Kaback HR. Engineering conformational flexibility in the lactose permease of Escherichia coli: Use of glycine-scanning mutagenesis to rescue mutant Glu325 $\rightarrow$ Asp. Biochemistry 2001;40:769-776. [PubMed: 11170394]

36. Sahin-Tóth M, le Coutre J, Kharabi D, le Maire G, Lee JC, Kaback HR. Characterization of Glu126 and Arg144, two residues that are indispensable for substrate binding in the lactose permease of Escherichia coli. Biochemistry 1999;38:813-819. [PubMed: 9888822]

37. Venkatesan P, Kaback HR. The substrate-binding site in the lactose permease of Escherichia coli. Proc. Natl. Acad. Sci. U.S.A 1998;95:9802-9807. [PubMed: 9707556]

38. Weinglass AB, Whitelegge JP, Hu Y, Verner GE, Faull KF, Kaback HR. Elucidation of substrate binding interactions in a membrane transport protein by mass spectrometry. EMBO J 2003;22:14671477. [PubMed: 12660154]

39. Klauda JB, Brooks BR. Sugar binding in lactose permease: Anomeric state of a disaccharide influences binding structure. J. Mol. Biol 2007;367:1523-1534. [PubMed: 17320103]

40. Menick DR, Sarkar HK, Poonian MS, Kaback HR. Cys154 is important for lac permease activity in Escherichia coli. Biochem. Biophys. Res. Commun 1985;132:162-170. [PubMed: 2998353]

41. Smirnova IN, Kaback HR. A mutation in the lactose permease of Escherichia coli that decreases conformational flexibility and increases protein stability. Biochemistry 2003;42:3025-3031. [PubMed: 12627968]

42. Nie Y, Sabetfard FE, Kaback HR. The Cys $154 \rightarrow$ Gly mutation in LacY causes constitutive opening of the hydrophilic periplasmic pathway. J. Mol. Biol 2008;379:695-703. [PubMed: 18485365]

43. Kasho VN, Smirnova IN, Kaback HR. Sequence alignment and homology threading reveals prokaryotic and eukaryotic proteins similar to lactose permease. J. Mol. Biol 2006;358:1060-1070. [PubMed: 16574153]

44. Carrasco N, Antes LM, Poonian MS, Kaback HR. Lac permease of Escherichia coli: Histidine-322 and glutamic acid-325 may be components of a charge-relay system. Biochemistry 1986;25:44864488. [PubMed: 2876725]

45. Carrasco N, Puttner IB, Antes LM, Lee JA, Larigan JD, Lolkema JS, Roepe PD, Kaback HR. Characterization of site-directed mutants in the lac permease of Escherichia coli. 2. Glutamate-325 replacements. Biochemistry 1989;28:2533-2539. [PubMed: 2567181]

46. Persson B, Roepe PD, Patel L, Lee J, Kaback HR. Site-directed mutagenesis of lysine 319 in the lactose permease of Escherichia coli. Biochemistry 1992;31:8892-8897. [PubMed: 1390676]

47. Sahin-Tóth M, Kaback HR. Properties of interacting aspartic acid and lysine residues in the lactose permease of Escherichia coli. Biochemistry 1993;32:10027-10035. [PubMed: 8399130]

48. Franco PJ, Brooker RJ. Functional roles of Glu-269 and Glu-325 within the lactose permease of Escherichia coli. J. Biol. Chem 1994;269:7379-7386. [PubMed: 7907327]

49. Sahin-Tóth M, Kaback HR. Arg-302 facilitates deprotonation of Glu-325 in the transport mechanism of the lactose permease from Escherichia coli. Proc. Natl. Acad. Sci. U.S.A 2001;98:6068-6073. [PubMed: 11353849]

50. Thompson AN, Posson DJ, Parsa PV, Nimigean CM. Molecular mechanism of pH sensing in KcsA potassium channels. Proc. Natl. Acad. Sci. U.S.A 2008;105:6900-6905. [PubMed: 18443286] 
51. Adam Y, Tayer N, Rotem D, Schreiber G, Schuldiner S. The fast release of sticky protons: kinetics of substrate binding and proton release in a multidrug transporter. Proc. Natl. Acad. Sci. U.S.A 2007;104:17989-17994. [PubMed: 17984053]

52. Boyer PD. Bioenergetic coupling to protonmotive force: Should we be considering hydronium ion coordination and not group protonation? Trends Biochem. Sci 1988;13:5-7. [PubMed: 2854307]

53. von Ballmoos C, Dimroth P. Two distinct proton binding sites in the ATP synthase family. Biochemistry 2007;46:11800-11809. [PubMed: 17910472]

54. Garczarek F, Brown LS, Lanyi JK, Gerwert K. Proton binding within a membrane protein by a protonated water cluster. Proc. Natl. Acad. Sci. U.S.A 2005;102:3633-3638. [PubMed: 15738416]

55. Garczarek F, Gerwert K. Functional waters in intra-protein proton transfer monitored by FTIR difference spectroscopy. Nature 2006;439:109-112. [PubMed: 16280982]

56. Esnouf RM. Further additions to MolScript version 1.4, including reading and contouring of electrondensity maps. Acta Crystallogr., Sect. D: Biol. Crystallogr 1999;55:938-940. [PubMed: 10089341]

57. Merritt EA, Bacon DJ. Raster3D: Photorealistic molecular graphics. Methods Enzymol 1977;277:504-524. 

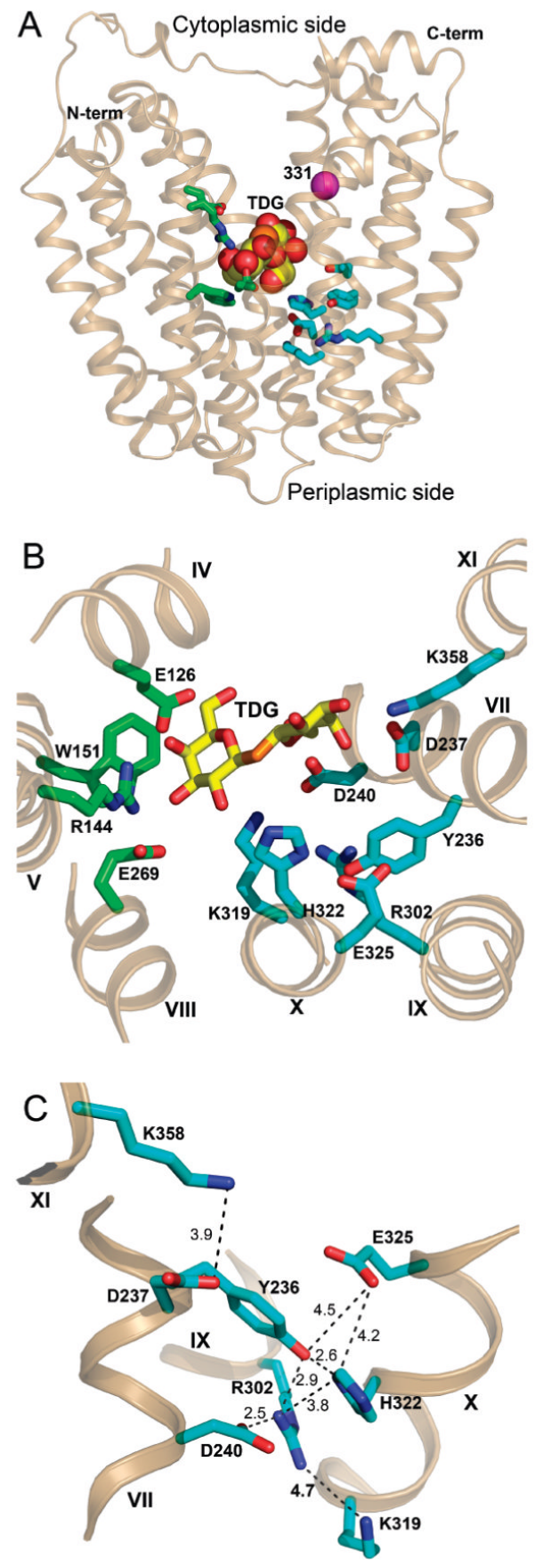

Figure 1.

X-ray structure model of LacY. (A) Side view of overall structure (PDB ID 1PV7) with TDG molecule (shown as spheres) bound at the apex of the cytoplasmic cavity. Amino acid residues implicated in sugar binding and $\mathrm{H}^{+}$translocation are shown as green or cyan sticks, respectively. The $\mathrm{C} \alpha$ atom at position 331, where the $\mathrm{Cys}$ residue introduced was labeled with fluorophore, is shown as a magenta sphere. (B) Cytoplasmic view from panel A showing part of the inner cavity with amino acid residues selected for mutational analysis and a TDG molecule shown as sticks. Transmembrane domains are labeled with Roman numbers. (C) Side view from the cytoplasmic cavity toward the proton translocation site (PDB ID 2CFQ). The network of hydrogen bond/salt bridge interactions is shown with only the shortest distances 
displayed as dashed lines (in $\AA$ ). The structures are presented using Pymol 0.97 (DeLano Scientific, LLC). 


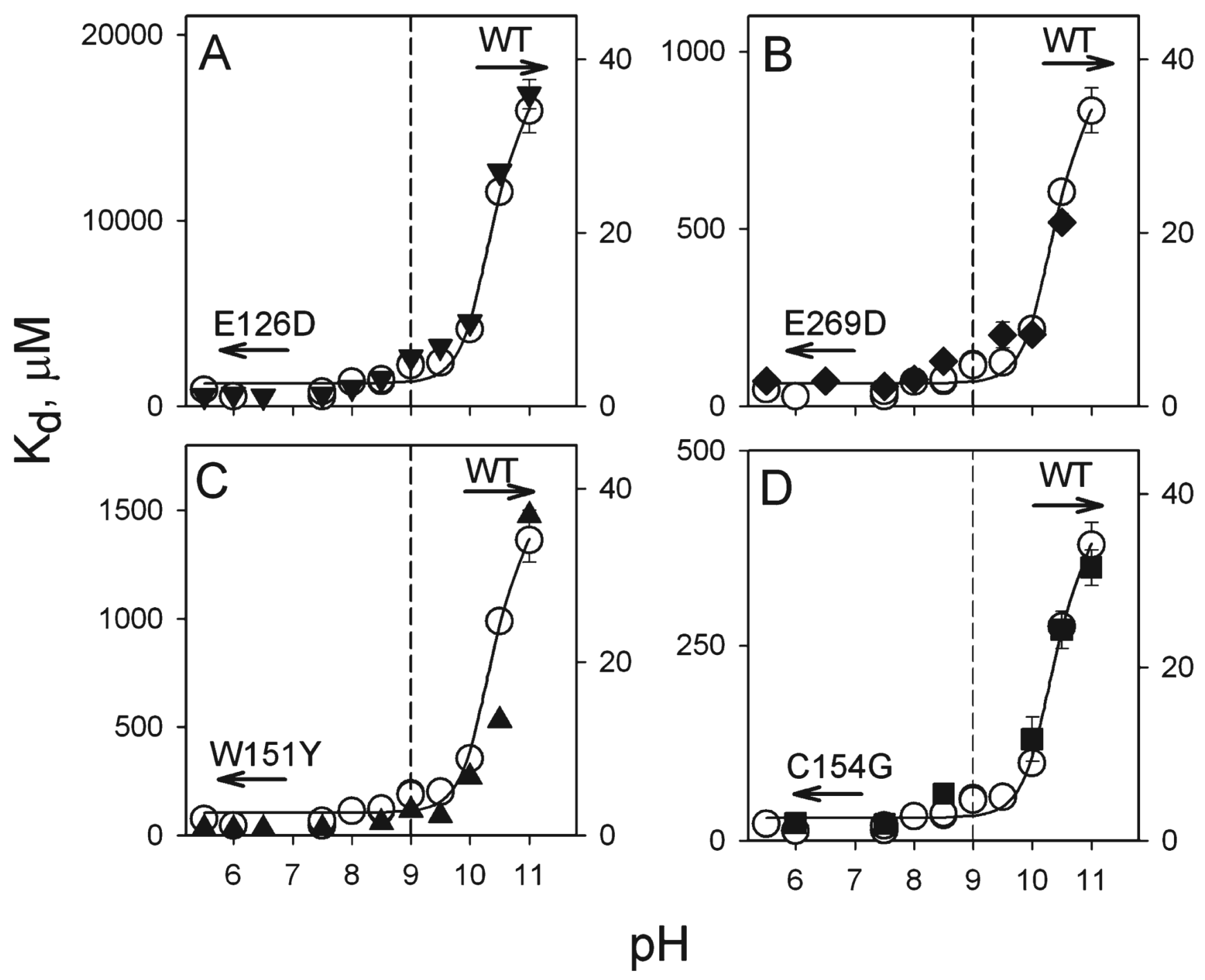

Figure 2.

Effect of $\mathrm{pH}$ on $K_{\mathrm{d}}$ app for TDG binding to MIANS-labeled V331C LacY with replacements of side chains in the vicinity of the sugar-binding site. Purified proteins $(0.4 \mu \mathrm{M})$ were titrated with TDG at the indicated $\mathrm{pH}$ as described in Materials and Methods. The titrations are presented in Supporting Information Figure 11. Estimated $K_{\mathrm{d}}$ app values are plotted versus $\mathrm{pH}$ and shown together with wild-type LacY data for comparison. The $\mathrm{p} K_{\mathrm{a}}$ value for wild-type LacY (10.5) is estimated from hyperbolic fit of $K_{\mathrm{d}}$ app dependency on $\mathrm{H}^{+}$concentration (solid line) (30). Vertical axes are as follows: on the right side for the wild-type LacY (O) and on the left side for the mutants (see arrows). The scales are proportional to the TDG affinity measured at pH 6.0 (see Table 1). (A) E126D ( $\boldsymbol{\nabla}$ ); (B) E269D ( ); (C) W151Y ( $\Delta$ ); (D) C154G (घ). The dashed vertical line marks $\mathrm{pH} 9.0$. 


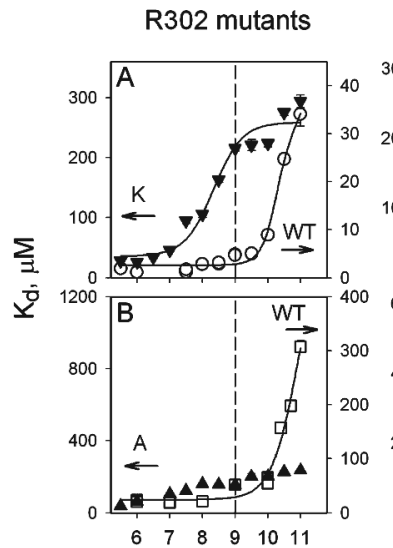

$\begin{array}{lllllll}6 & 7 & 8 & 9 & 10 & 11\end{array}$
Y236 mutants

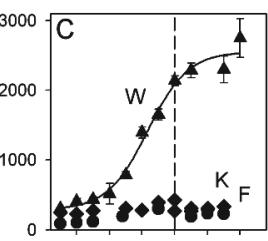

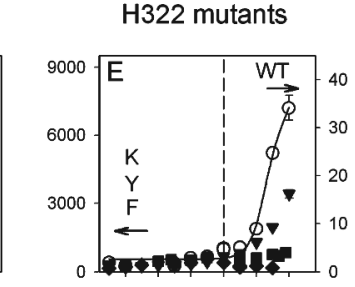
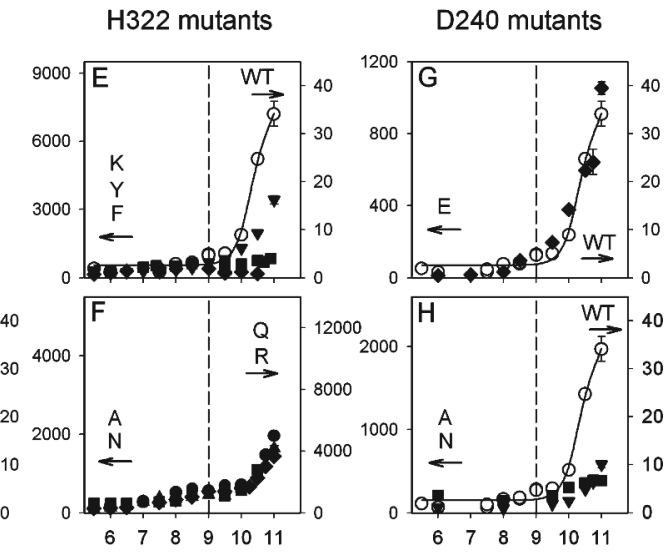

$\mathrm{pH}$

Figure 3.

Effect of $\mathrm{pH}$ on $K_{\mathrm{d}}$ app for TDG binding to the LacY mutants with replacements in $\mathrm{H}^{+}$ translocation site at positions of Arg302, Tyr236, His322, and Asp240. Data for mutated residues (marked on the top) are presented on upper and lower panels. Side chain replacements are shown on each panel as single letters together with arrows indicating the vertical axes for $K_{\mathrm{d}}$ app values. Titrations were carried out as described in Materials and Methods and in Figure 2 (see also Supporting Information Figures 12-14). Data for wild-type LacY (open symbols) are shown for comparison. MIANS-labeled V331C LacY was used in all experiments except R302A that was labeled with DACM and compared to DACM-labeled wild type (panel B). Vertical scales are proportional to $K_{\mathrm{d}}$ app at pH 6 for wild-type LacY (see Table 1). (A) R302K

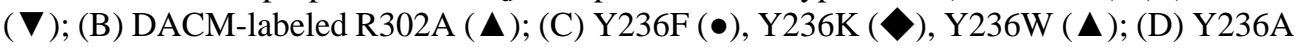

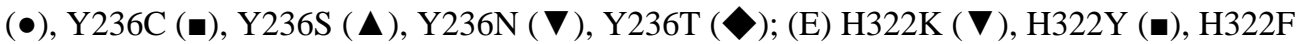

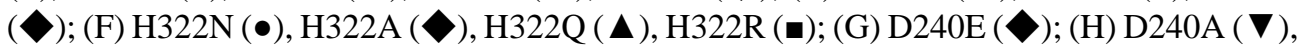
$\mathrm{D} 240 \mathrm{~N}(\boldsymbol{\square}), \mathrm{p} K_{\mathrm{a}}$ values are estimated from hyperbolic fit of $K_{\mathrm{d}}$ app dependency on $\mathrm{H}^{+}$ concentration (solid lines) as shown in Supporting Information Figure 16 and presented in Table 1. 


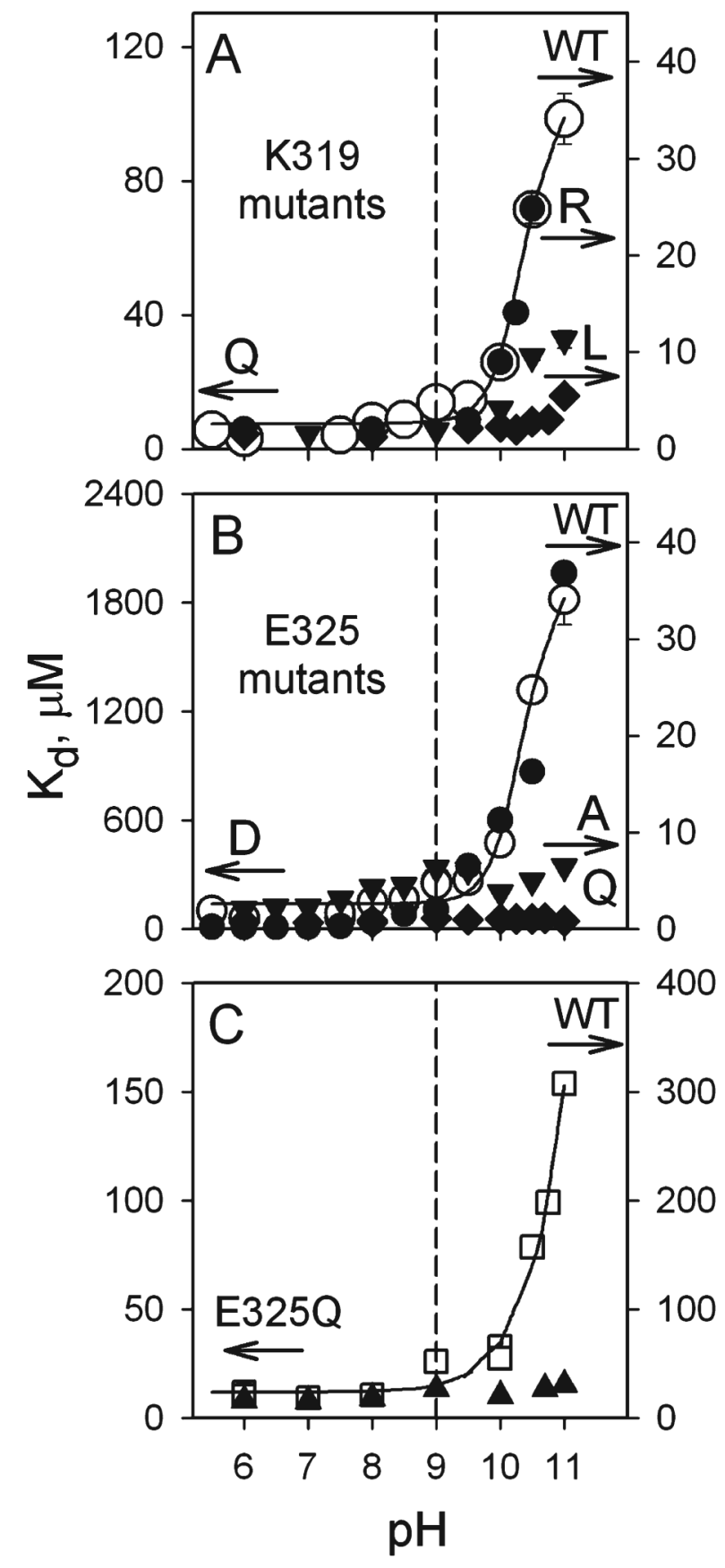

Figure 4.

Effect of $\mathrm{pH}$ on $K_{\mathrm{d}}$ app for TDG binding to the LacY mutants with replacements of Lys319 and Glu325. MIANS-labeled proteins were used in panels A and B; DACM-labeled E325Q and wild type were used in panel C. Data are analyzed and presented in Figures 2 and 3 (see also Table 1 and Supporting Information Figure 15). (A) K319R (•), K319L ( ), K319Q ( $)$ ); (B) E325D (•), E325A ( $\boldsymbol{\nabla})$, E325Q $(\bullet)$; (C) DACM-labeled E325Q ( $\Delta$ ). Data for wild-type $\mathrm{LacY}$ (open symbols and solid lines) are shown for comparison. 
WT

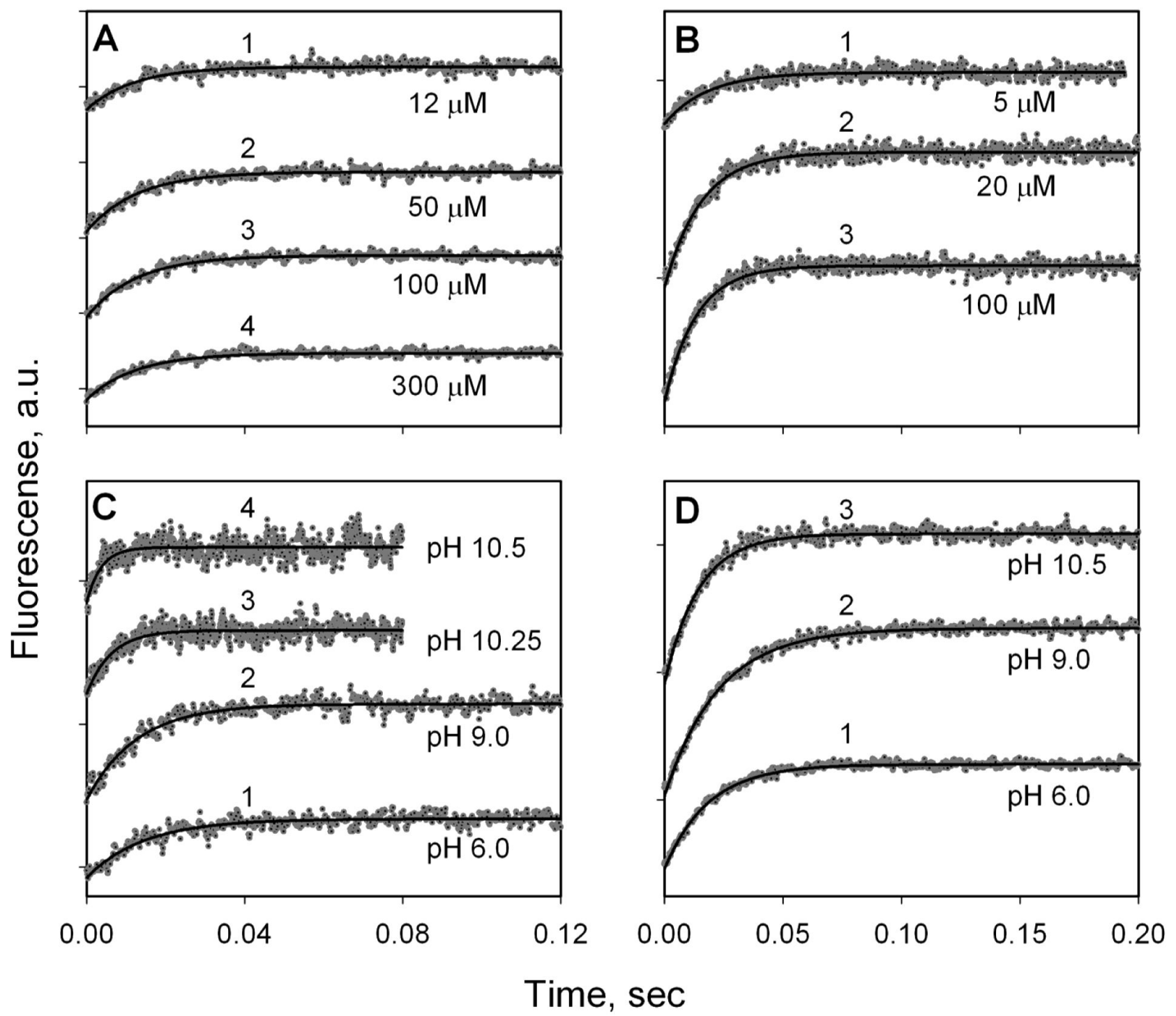

Figure 5.

Stopped-flow traces of Trp fluorescence change showing displacement of bound NPG by the excess of TDG at various NPG concentrations and different $\mathrm{pHs}$. Average of seven to nine individual traces (gray dots) are fitted with a single exponential equation (solid lines). Amplitudes are calculated as percentage of fluorescence change relative to the final level of fluorescence. (A) WT LacY at pH 9.0 and indicated NPG concentrations. Amplitudes of fluorescence change are $9 \%, 16 \%, 22 \%$, and $25 \%$ for traces $1,2,3$, and 4, respectively. Estimated $k_{\text {off }}$ is $80 \pm 2 \mathrm{~s}^{-1}$. (B) K319L LacY at pH 10.5 and indicated NPG concentrations. Amplitudes of fluorescence change are 9\%, 26\%, and 33\% for traces 1, 2, and 3, respectively. Estimated $k_{\mathrm{off}}$ is $70 \pm 5 \mathrm{~s}^{-1}$. (C) WT LacY, $\mathrm{pH}$ dependence of displacement rate. Estimated

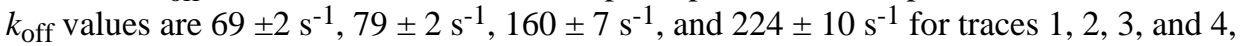
respectively. (D) K319L LacY, pH dependence of displacement rate. Estimated $k_{\text {off }}$ values are $54 \pm 2 \mathrm{~s}^{-1}, 44 \pm 4 \mathrm{~s}^{-1}$, and $69 \pm 10 \mathrm{~s}^{-1}$ for traces 1,2 , and 3, respectively. See Materials and Methods for details. 
WT
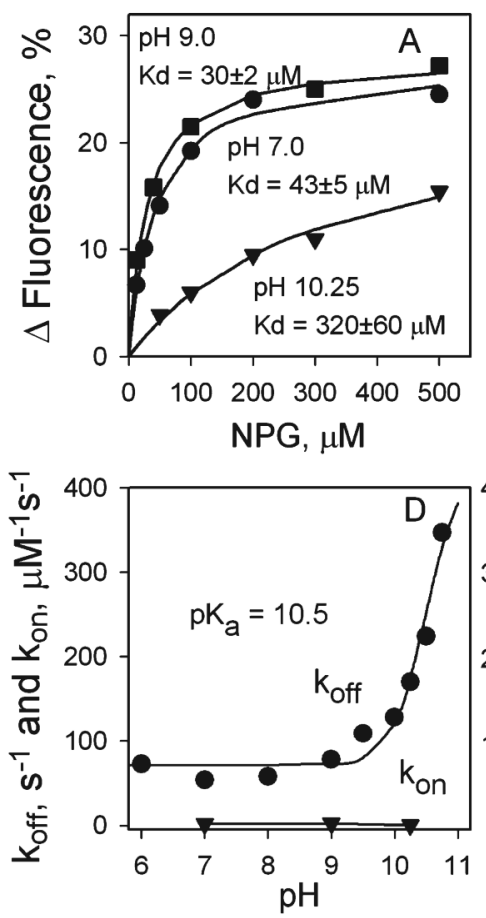

K319L
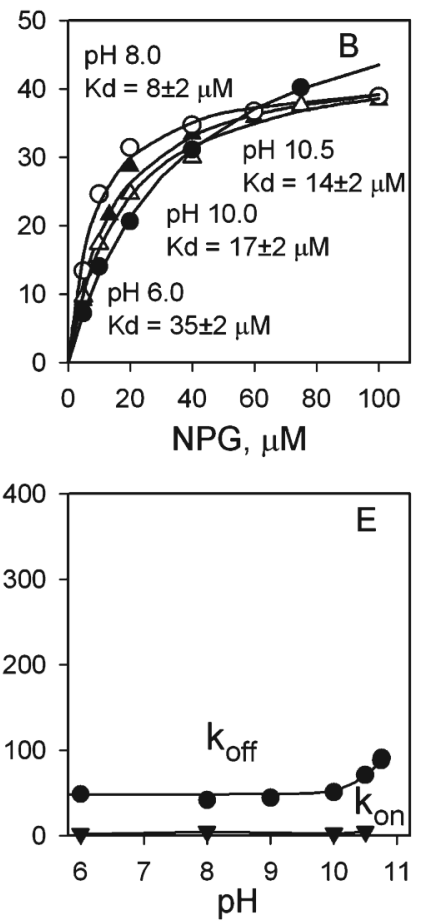

K319F
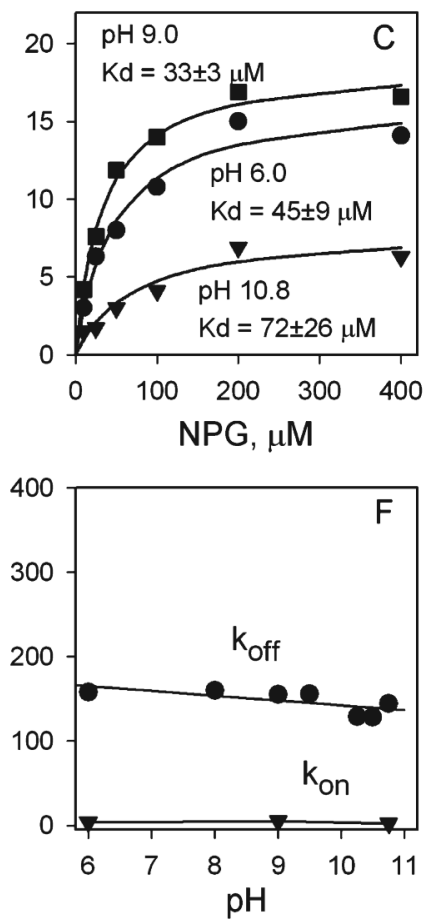

Figure 6.

Kinetics of displacement of bound NPG by the excess of TDG; comparison of WT LacY with uncharged replacements for Lys319. Upper panels: Dependence of amplitude of fluorescence changes on NPG concentrations at different $\mathrm{pH}$. Solid lines are hyperbolic fits to the data. Calculated $K_{\mathrm{d}}$ values at each $\mathrm{pH}$ are indicated. Lower panels: $\mathrm{pH}$ dependencies of measured displacement rates ( $\left.k_{\text {off }}\right)$ and $k_{\text {on }}$ calculated from $K_{\mathrm{d}}\left(k_{\text {on }}=k_{\text {off }} / K_{\mathrm{d}}\right)$ are presented as circles and triangles, respectively. 
E325A
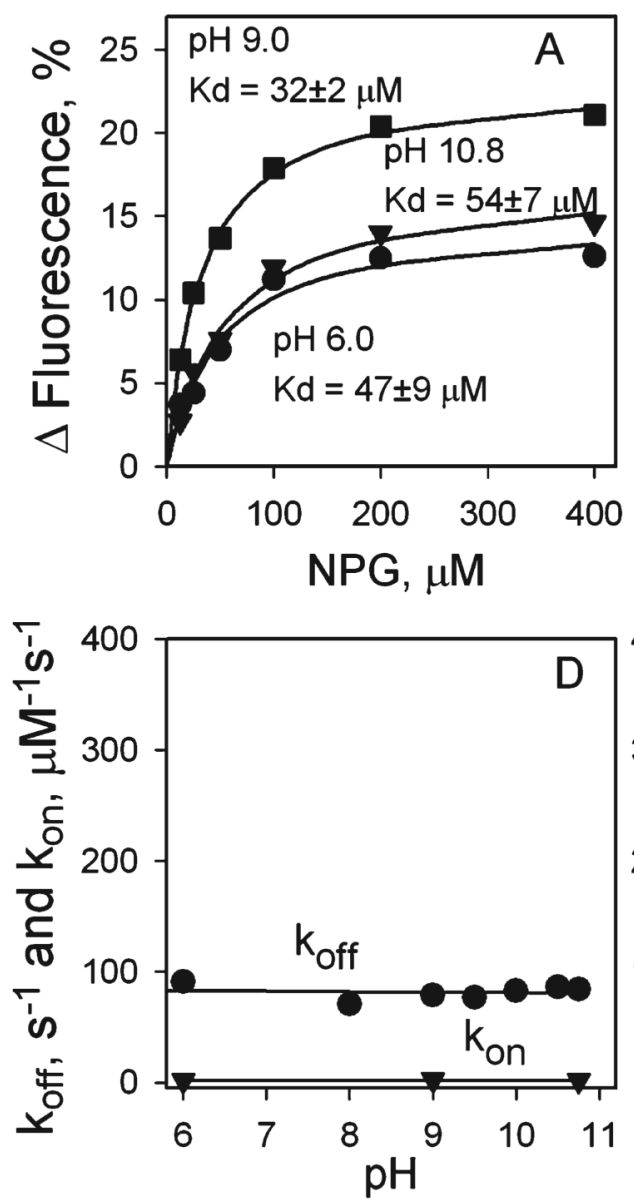

$E 325 Q$
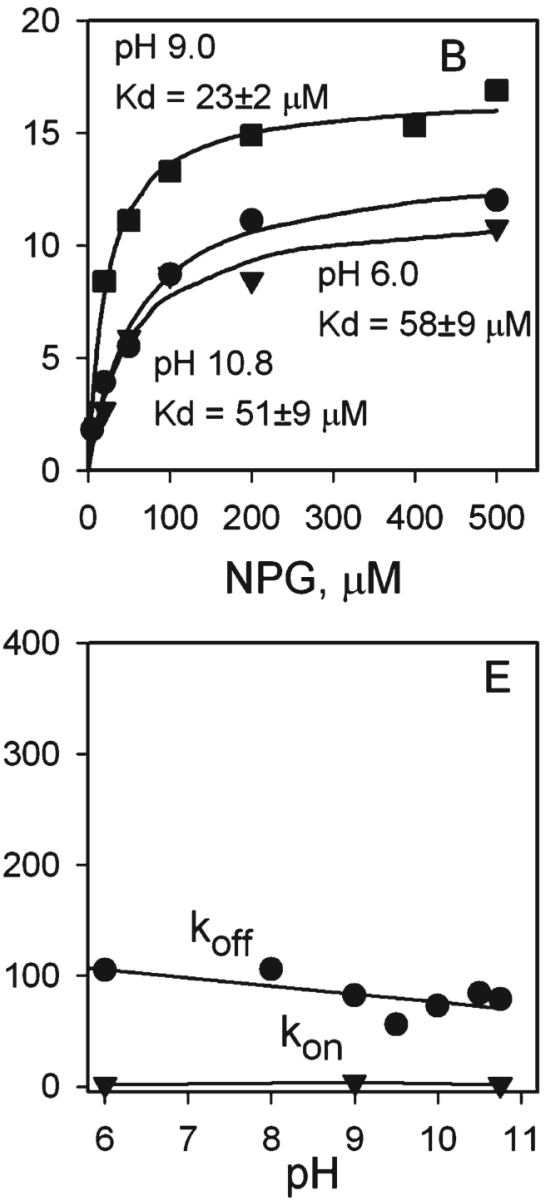

E325W
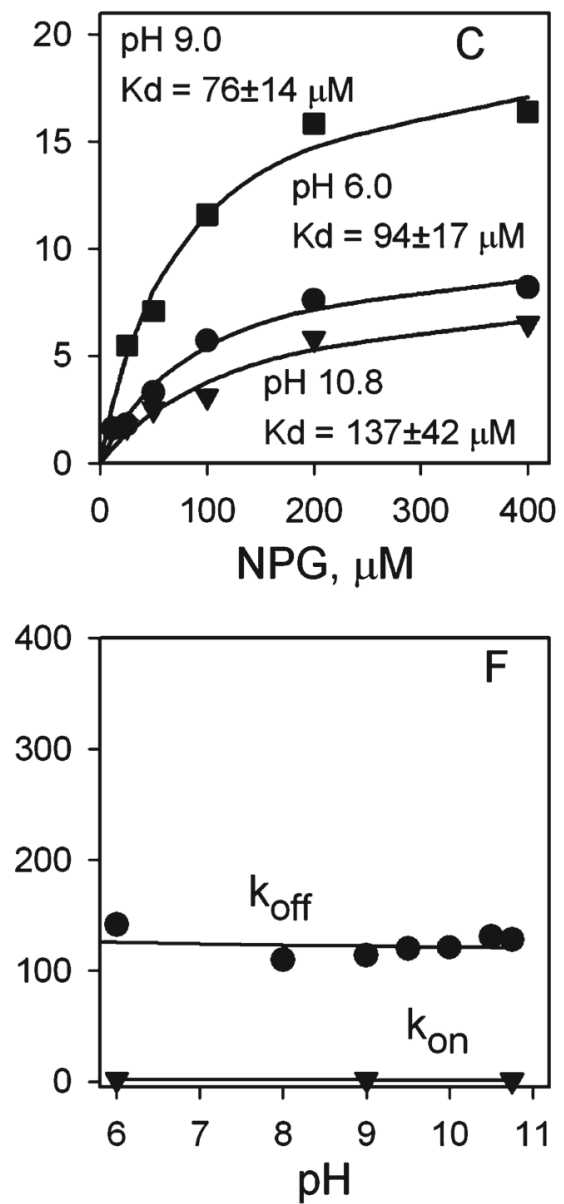

Figure 7.

Kinetics of displacement of bound NPG by the excess of TDG for uncharged replacements of Glu325. Upper panels: Dependence of amplitude of fluorescence changes on NPG concentrations at different $\mathrm{pHs}$. Solid lines are hyperbolic fits to the data. Calculated $K_{\mathrm{d}}$ values at each $\mathrm{pH}$ are indicated. Lower panels: $\mathrm{pH}$ dependencies of measured displacement rates $\left(k_{\mathrm{off}}\right)$ and $k_{\mathrm{on}}$ calculated from $K_{\mathrm{d}}$ are presented as circles and triangles, respectively. 
K319L/E325Q
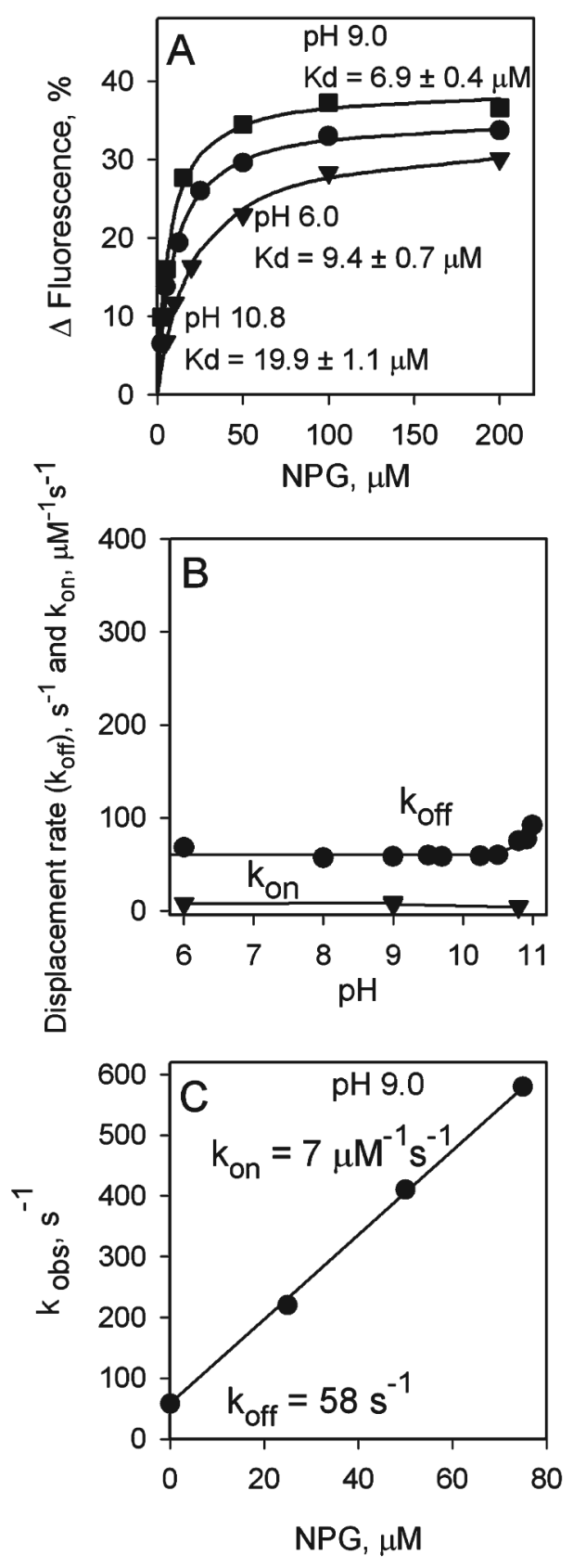

Figure 8.

Kinetics of NPG binding to the LacY mutant K319L/E325Q. (A, B) Displacement of bound NPG by the excess of TDG. Measurements are carried out as in Figure 5-7. (A) NPG concentration dependence of amplitude of fluorescence change at $\mathrm{pH} 6.0(\bullet), 9.0(\mathbf{\bullet})$, and 10.8 $(\boldsymbol{\nabla})$. Solid lines are hyperbolic fits to the data. Calculated $K_{\mathrm{d}}$ values at each $\mathrm{pH}$ are shown. (B) Dependence of the rates of fluorescence increase on $\mathrm{pH}$. Measured $k_{\text {off }}$ is $64 \pm 8 \mathrm{~s}^{-1}$ in the $\mathrm{pH}$ range 6.0-10.8 ( $k_{\text {off }}$ at $\mathrm{pH} 9.0$ is $\left.58 \mathrm{~s}^{-1}\right)$. The $k_{\text {on }}$ values $\left(6.5 \pm 2.4 \mu \mathrm{M}^{-1} \mathrm{~s}^{-1}\right)$ are calculated from measured $k_{\text {off }}$ and $K_{\mathrm{d}}$. (C) Binding of NPG to the LacY mutant at $\mathrm{pH} 9.0$ measured directly. Protein $(0.5 \mu \mathrm{M})$ was rapidly mixed with NPG at the indicated concentrations, stopped-flow traces were recorded, and the rates of fluorescence decrease $\left(k_{\mathrm{obs}}\right)$ were estimated from 
exponential fits to the data. All given concentrations are final after mixing. NPG concentration dependence of $k_{\mathrm{obs}}$ is presented. Each point is an average of seven to nine measurements. The solid line is the linear fit to the data $\left(k_{\mathrm{obs}}=k_{\mathrm{off}}+k_{\mathrm{on}}[\mathrm{NPG}]\right)$. The slope is $k_{\mathrm{on}}\left(7 \mu \mathrm{M}^{-1} \mathrm{~s}^{-1}\right)$ and the intercept with the $y$ axis is $k_{\mathrm{off}}\left(58 \mathrm{~s}^{-1}\right)$. The $k_{\mathrm{off}}$ value for NPG measured directly is exactly the same as measured by displacement of bound NPG with the excess of TDG (panel B). The estimated $K_{\mathrm{d}}(8.3 \mu \mathrm{M})$ is in a good agreement with $K_{\mathrm{d}}$ measured by displacement (panel A). 
R302A
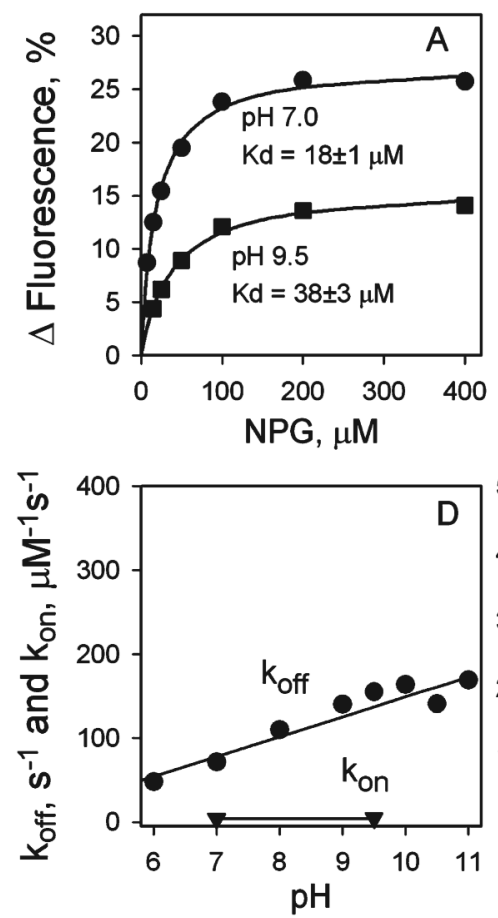

D240E

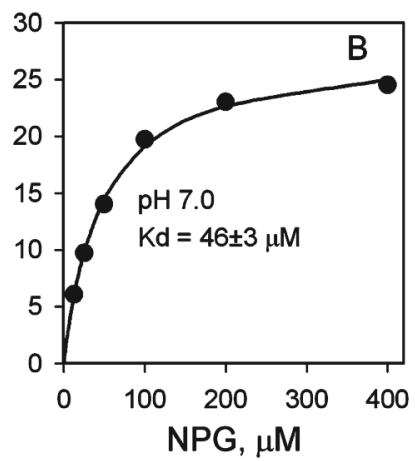

D240A

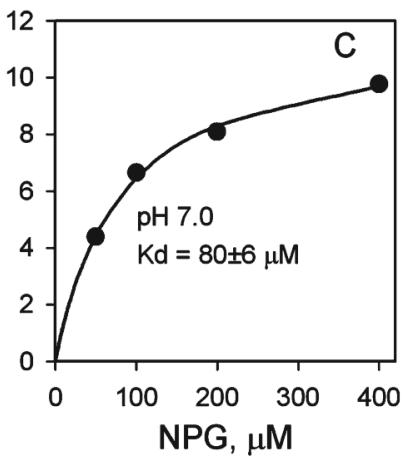

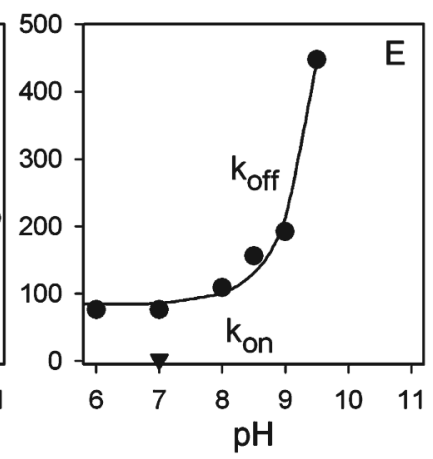

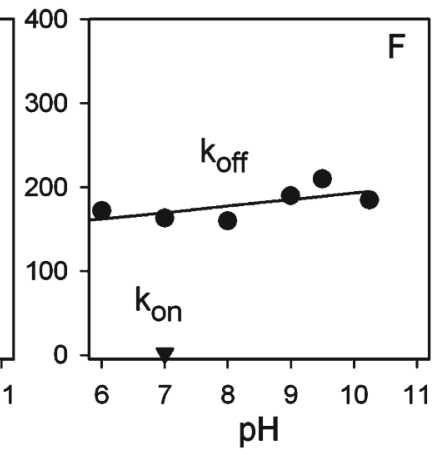

Figure 9.

Kinetics of displacement of bound NPG by the excess of TDG: data for mutants R302A, D240E, and D240A. Upper panels: Dependence of amplitude of fluorescence changes on NPG concentrations at different $\mathrm{pHs}$. Solid lines are hyperbolic fits to the data. Calculated $K_{\mathrm{d}}$ values at each $\mathrm{pH}$ are indicated. Lower panels: $\mathrm{pH}$ dependencies of measured displacement rates $\left(k_{\mathrm{off}}\right)$ and $k_{\mathrm{on}}$ calculated from $K_{\mathrm{d}}$ are presented as circles and triangles, respectively. 


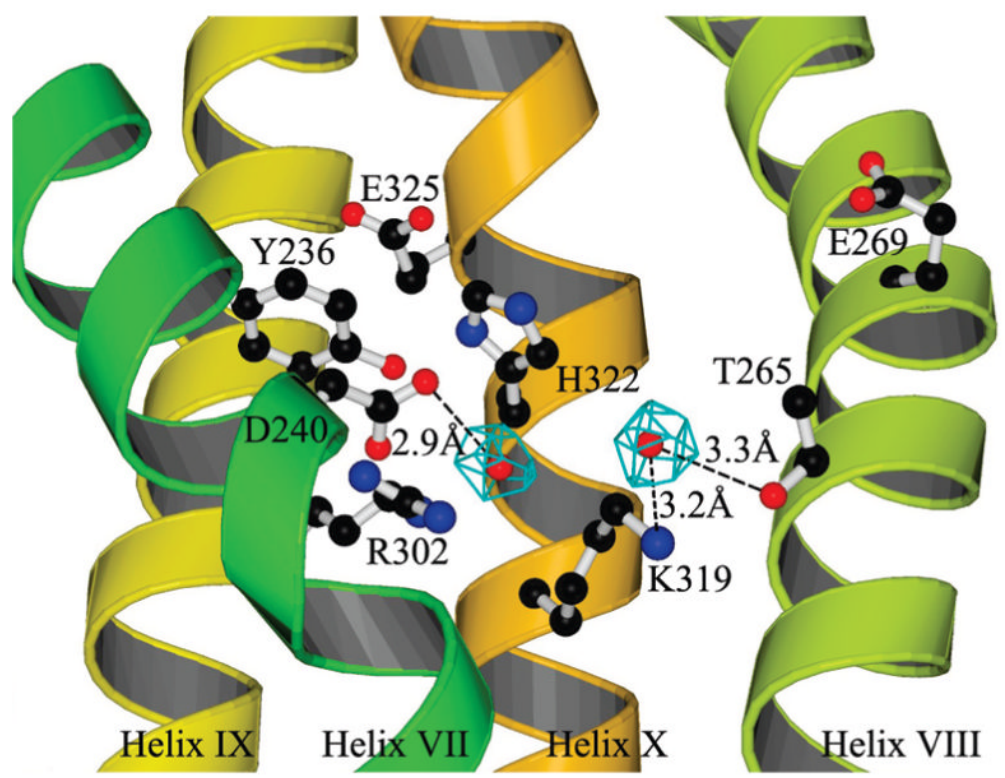

Figure 10.

Water molecules in the $\mathrm{H}^{+}$translocation site of the refined LacY structure. Side view shown from the cytoplasmic cavity toward the $\mathrm{H}^{+}$translocation site. Residues important for $\mathrm{H}^{+}$ translocation are displayed as balls and sticks, and water molecules are presented as red balls surrounded by globular densities in mesh presentation (shown with $2 \sigma$ contour level). H-bonds between waters and amino acid residues are drawn as broken lines with distances in $\AA$. See Supporting Information Refinement of LacY Structure for details. Illustration prepared using BobScript and Raster3D (56,57). 
